\title{
Prehabilitation: The Void in the Management of Anterior Cruciate Ligament Injuries-A Clinical Review
}

\author{
S. R. Shaarani, ${ }^{1}$ N. Moyna, ${ }^{2}$ R. Moran, ${ }^{3}$ and J. M. O’Byrne ${ }^{4}$ \\ ${ }^{1}$ Royal College of Surgeons in Ireland, 123 St. Stephens Green, Dublin 2, Ireland \\ ${ }^{2}$ School of Health and Human Performance, Dublin City University, Dublin 9, Ireland \\ ${ }^{3}$ Department of Orthopaedic Surgery, Sports Surgery Clinic, Santry Demesne, Dublin 9, Ireland \\ ${ }^{4}$ Department of Orthopaedic Surgery, Cappagh National Orthopaedic Hospital, Finglas, Dublin 11, Ireland \\ Correspondence should be addressed to N. Moyna, niall.moyna@dcu.ie
}

Received 18 January 2012; Accepted 16 February 2012

Academic Editors: S. Ristanis, T. E. Towheed, and P. Wretenberg

Copyright ( $) 2012$ S. R. Shaarani et al. This is an open access article distributed under the Creative Commons Attribution License, which permits unrestricted use, distribution, and reproduction in any medium, provided the original work is properly cited.

The rehabilitation of patients undergoing anterior cruciate ligament (ACL) reconstruction requires symmetry in bilateral quadriceps strength and adequate proprioception capabilities prior to return to preoperative level of activity or sport. This is the limiting factor and can delay the time that patients can return to play. There is little literature on pre-operative physiotherapy or prehabilitation of patient with ACL injury. This paper discusses the anatomy, biomechanics, surgical decision making, and the current knowledge of preoperative training or "prehabilitation" in patients awaiting ACL reconstruction.

\section{Introduction}

Anterior cruciate ligament injuries are significant when they involve a complete intrasubstance tearing of the anterior cruciate ligament (ACL) in the knee. The injury is characterized by joint instability that leads to pain, decreased activity and function, poor-knee-related quality of life, and an increased risk of osteoarthritis of the knee. Relatively few studies have examined the effects of preoperative strengthening of the ACL injured patient. Most studies on ACL rehabilitation in the recent past have mainly investigated (i) the coping mechanisms of the patients treated conservatively, (ii) the effects of balance training preoperatively, (iii) the outcomes of accelerated rehabilitation postoperatively, (iv) and the types of rehabilitation programmes that should be employed.

Prehabilitation has been defined as "the process of enhancing functional capacity of the individual to enable them to withstand the stressor of inactivity" [1], preparing a patient before a stressful event. The term "prehabilitation" is not commonly used in the context of ACL injury rehabilitation. It is, however, used in relation to patients preparing for other orthopaedic procedures [1] and in prevention of injury in the healthy population [2]. For example, prehabilitation is commonly used prior to total knee replacements [3], spine surgery [4], cardiac procedures [5], and colectomies [6]. Noyes et al. were the first to propose the use of physiotherapy prior to ACL surgery to increase muscle strength and improve recovery rates [7]. However, to date, very few studies examined the effects of preoperative physiotherapy in this condition.

There has been a paradigm shift from Noyes's ruleof-one-third in relation to ACL injuries, where a third improved, another third deteriorated, and the final third had no significant changes following rehabilitation and activity modification. The pathway of ACL injuries is shown in Figure 1. With the advent of MRI technology and improvement in arthroscopic surgical techniques, ACL injuries are identified and managed in a more timely manner. Conservative nonsurgical management has its benefits, but new evidence shows that the biomechanical properties of the ACL remnants after an ACL injury does not provide knee joint stability at 1 year after injury [8]. This may be important as to suggest that ACLR is a vital decision to undertake within one year after an ACL injury [9]. The advancement of improving the standard for ACL surgical intervention, and their pre- and post-operative management including rehabilitation is still being pursued. This paper discusses the anatomy, biomechanics, surgical decision making, and the 


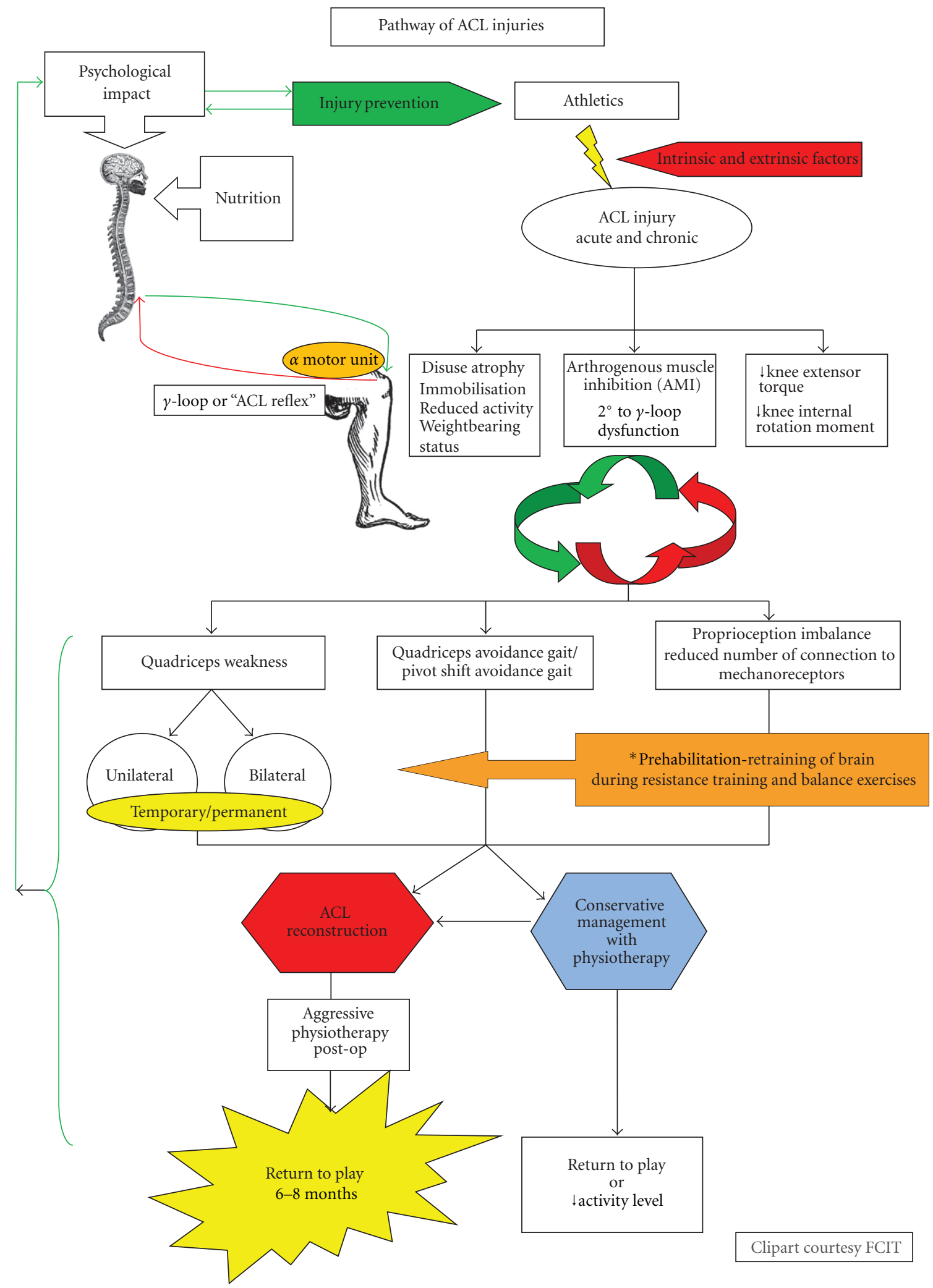

FIGURE 1: The pathway of the ACL-injured patient and the role of prehabilitation to reduce the effect of preoperative quadriceps weakness, abnormal gait, and proprioception difficulties. 
current knowledge of preoperative training or "prehabilitation" in patients awaiting ACL reconstruction.

\section{Anatomy}

The anterior cruciate ligament (ACL) is one of the 4 main ligaments in the knee. Embryologically, the ACL is developed by the condensation and differentiation of the blasternal tissue of the interchondral disc which occur from the sixth to the eighth weeks of intrauterine life $[10,11]$. The ligament is surrounded by a fold of synovium that originates from the posterior capsule of the knee joint. Therefore, even though the ACL is located intra-articularly, it is developmentally an extrasynovial structure.

Macroscopically, the mature ACL originates from the medial aspect of the lateral femoral condyle in the intercondylar notch and inserts into the interspinous area of the tibia [12]. The ACL is composed of the anteromedial bundle (AMB), which is tight in flexion and limits the anterior translation of the tibia in relation to the femur. The posterolateral bundle (PLB) is tight in extension and limits anterior translation to the tibia, but also assists in limiting external rotation [13]. The average ACL length is $38 \mathrm{~mm}$ with an average width of $11 \mathrm{~mm}$ [14].

On a microscopic level, the ACL is composed of multiple bundles of mainly collagen units arranged in fascicles. The proximal part of the ligament is the most cellular with abundance of round and ovoid cells. The mid-substance has a high percentage of collagen with low cellularity and elongated spindle-shaped fibroblast. The distal portion is the most solid part of the structure, which is rich with chondroblast and ovoid fibroblasts but low in collagen bundles $[15,16]$.

The ACL is innervated by the posterior articular branch of the tibial nerve. The nerve fibres penetrate through the posterior joint capsule and accompany the adjacent synovium and vasculature to reach as far as the infrapatellar fat pad [17]. Most of these fibres have a vasomotor function. However, several small myelinated and unmyelinated fibres are present within the ligament in isolation and are independent of the blood supply. These receptors include Ruffini, Vater-Pacini, and Golgi-like tension receptors as well as free nerve endings $[17,18]$. The former three tension receptors are mechanoreceptors that are important in proprioception and provide important signalling pathways during knee postural changes [19].

Structural changes within the ACL have a direct effect on the output of muscle spindles through the fusimotor system and its gamma motor neurons. It is these changes that influence the motor activity around the knee and are termed the "ACL reflex" [20]. This neurostructural system is an essential part of normal everyday activities of the knees which influences the functionality of associated muscle groups.

\section{Biomechanics of a Normal ACL}

The ACL is integral for joint stability and is the primary restraint to anterior translation of the tibia relative to the femur
[21]. The four-bar linkage cruciate mechanism constrains the motion of the femur on the tibia so that there is an effective combination of rolling and sliding movements [22]. This model is simplistic in its explanation of knee motion in the sagittal plane but fails to take into account the rotational components of the femorotibial joint. In native knees, the ACL limits anterior neutral-position shift. In contrast, chronic ACL-deficient knees associated with ACL injuries causes anterior translation of the tibia relative to the femur which is four times greater than normal knees [23]. The ACL supports a restraint of approximately $85 \%$ to the applied anterior load at 30 degrees of flexion of the knee. This decreases to $80 \%$ at 90 degrees of flexion [23].

The AMB and PLB bundles have different mechanisms of action when an anterior draw force is applied to the knee. In vitro studies have found that AMB of the ACL has an in situ tension that increased as the knee flexed from 20 to 90 degrees. In contrast, the force in the PLB increased during knee extension [24, 25]. PLB dominance in the extended knee provides a basis for developing doublebundle reconstructions.

When the knee joint is near full extension, the ACL functions as an important secondary restraint to internal rotation. Additionally, the ACL provides a minor secondary restraint to external rotation and varus-valgus angulation, especially during weightbearing conditions [26]. This can be tested clinically with the "pivot shift test" which involves applying a combined internal tibial and valgus torque throughout the range of flexion extension [27]. Woo et al. studied the tensile properties of the femur-ACL-tibia complex and found that ultimate tensile load to failure and stiffness for young specimens (22-35 years) were 2,160 N and $242 \mathrm{~N} / \mathrm{mm}$, respectively [28]. Ultimate tensile load and linear stiffness decrease significantly with age [28].

\section{Biomechanics in ACL-Deficient Knees and ACLR Patients}

Biomechanical studies of rehabilitated individuals with ACLdeficient knees and ACLR have shown different joint torques in the lower limbs during walking compared with healthy controls. ACL injured patients eventually develop a greater extensor torque at the hip and a reduced extensor torque at the knee during the stance phases of walking and running [29-32]. These observations have been supported by increased electromyographic (EMG) activity in the hamstrings and reduced EMG activity in the quadriceps in ACL-deficient patients during the gait cycle [33-39]. These adaptations are advantageous to individuals with both ACL deficiency and ACLR because they reduce anterior displacement of the tibia relative to the femur and therefore reduce stress on the knee joint while also enabling individuals to perform complex knee movements [29-31, 38, 40].

The symptoms of knee instability with ACL rupture occur during weight acceptance of the injured limb in the early stance phase of the gait cycle. During this phase of the cycle, the limb accepts full support of the body and attenuates shock via knee flexion, which is controlled by an eccentric 
contraction of the quadriceps. When symptoms of knee instability are felt, patients alter their movement patterns through reduced knee flexion and internal knee extensor moments [30, 41]. The alteration in movement pattern results from the hesitancy to fully activate the quadriceps muscles at a range close to full knee extension. Berchuck et al. [30] termed this alteration as "quadriceps avoidance" due to the fact that close to full knee extension, quadriceps contraction may cause anterior tibial translation $[42,43]$ that in turn could result to the symptoms of giving way. The alteration in movement pattern associated with "quadriceps avoidance," may also represent an increase flexor activity of the hamstrings [44], or the gastrocnemius [45] which have been supported by EMG studies. However, altered movement patterns persist following ACLR $[46,47]$, suggesting that instability is not the sole cause of the gait adaptation.

There is also evidence that ACL-deficient patients walk with a significantly lower internal rotation knee joint moment during the terminal stance phase of the gait cycle [48-50]. Like the adaptation in the early stance phase of gait, this phenomenon is also likely adopted to prevent rotational instability. Termed as the "pivot-shift avoidance," this gait is also characterized by a significantly decreased internal rotation knee joint moment and by a significantly higher flexion angle during the terminal stance phase of the gait cycle.

Although a number of studies have applied bioinformatic modelling and simulation to understand the muscular adaptations of the gait cycle $[47,51,52]$, only one of these has quantified the effect of muscle compensation on knee instability in ACL-injured patients. Liu and Maitland found that $56 \%$ of peak isometric hamstrings force was required to restore anterior tibial translation in the ACL-deficient knee to the values observed in normal gait [53]. This study was performed at the single instant of the gait cycle (heel strike) and only considered the effect of hamstrings muscle action on anterior tibial translation during normal gait speeds.

\section{Causes of Quadriceps Weakness}

The quadriceps muscles are the principle extensors of the lower limb. It becomes active during the end of the swing phase of the gait cycle and contracts concentrically during knee extension such as rising from a sitting/squatting position, climbing upstairs, and during running and acceleration. It contracts eccentrically during walking down a slope. Decreased levels of physical activity [54-56], weightbearing status [56-58], and immobilization [59-61] can lead to progressive atrophy. Several factors including decreased protein synthesis [62-64], increased levels of plasma cortisol [65], arthrogenic inhibition [66, 67], and altered afferent inflow [66] may be responsible for atrophy after trauma or in periods of prolonged muscular disuse. Though evidence is lacking, this notion alone supports the possible benefits of prehabilitation in preoperative ACL-deficient patients.

Research of quadriceps muscle atrophy and muscle strength has employed various measurements such as crosssectional area (CSA) and muscle volume, muscle torque, and morphological measures by fibre-typing to find their correlation. Most studies failed to show a relation between quadriceps muscle CSA, morphological measures, and muscle strength in ACL-deficient patients $[66,68,69]$. Muscle volume appears to be a better indicator for atrophy than muscle torque because the latter is patient-dependent [70]. Measurable atrophy can be observed within 1 to 2 weeks and progresses exponentially $[56,59]$. The vastus lateralis and medialis (VL and VM, resp.) each have approximately 50\% type I fibre composition [71]. Both types I and II muscle fibres atrophy significantly, with greater effect on type I fibers $[60,62,63]$. A concomitant shift from type I to type II (slow-to-fast fibres) is also found [58]. Motor units are also recruited in a consistent fashion from type I to type II.

Disuse muscle atrophy is a known cause of quadriceps weakness. Extensor torque and quadriceps cross-sectional area decreased by $25-30 \%$ and by $14 \%$, respectively after 6 weeks of bed rest in healthy volunteers [72]. Berg et al. reported similar results and interestingly found that these changes were completely reversed after 7 weeks of recovery [73]. A reduction of strength power likely caused by altered neural function may precede atrophy in periods of decreased activity [65]. Failure of voluntary activation from the central nervous system to the quadriceps muscle as a result of disruption of the ACL has been implicated [74]. Konishi et al. have found abnormal gamma loop function in the involved and uninvolved quadriceps muscle of patients with ACL rupture [75]. There is loss of feedback from ACL mechanoreceptors which results in a suppressed state of recruitment of high-threshold motor units, presumably through the elimination of feedback to gamma motor neurons [76]. This mechanism is also called reflex inhibition or athrogenous muscle inhibition (AMI). This is a protective mechanism prevent future reinjury. Stevens et al. found the incidence of activation failure in young healthy subjects is approximately $10 \%$ [77]. In ACL-deficient subjects the incidence of complete inactivation is approximately $30 \%$ and can be bilateral [78]. Adjusting contralateral knee strength for activation and considering the activation of the involved quadriceps may allow for a more accurate assessment of the relative contribution of atrophy and activation failure to the quadriceps weakness that occurs after ACL rupture. Quadriceps muscle strength is a significant determinant of functional ability of the ACLR knee joint [79]. Considering emerging evidence linking bilateral quadriceps weakness with unilateral ACL injury, there is a need to further investigate the role of bilateral quadriceps strengthening prior to ACLR.

A biomechanical explanation such as a reduction in quadriceps moments may also be related to quadriceps weakness despite ACLR [80]. Quadriceps moment refers to the force generated from the local structures of muscles and tendon across the knee joint. Lewek et al. tested individuals with complete ACL rupture who had $>90 \%$ or $<80 \%$ of quadriceps strength using walking and jogging motions [79]. A percentage of these patients underwent ACLR. None of the ACLR patients had a disruption in the extensor mechanism during reconstruction during an allograft or hamstring reconstruction. Compared to the uninjured group, there was 
a significant reduction in knee moment at peak knee flexion in both the weak ACLR (quadriceps strength <80\%) and ACL-deficient group during the early stance phase of walking and jogging. However, whether this is due to quadriceps weakness or an increased activity of the hamstrings could have been further clarified with EMG studies.

While quadriceps strength is often used as a marker for rehabilitation progress "return to play," guidelines following ACLR are not clearly defined and vary considerably [81, 82]. A quadriceps index of $65 \%$ and $>80 \%$ is often used as a criteria for a return to sport-specific training and full competition, respectively $[81,82]$. A full range of motion (ROM) of the knee, with no evidence of an effusion, and self-report of normal activities without symptoms have also been used as criteria allowing patients to return to full activities [83]. However, another study showed that patients with a quadriceps index of $<80 \%$ had walking and jogging pattern similar to patients with ACL deficiency, indicating that premature activities may in fact be detrimental to joint integrity.

\section{Decision Making Prior to Surgery}

The ultimate goal of ACLR is the restoration of stability [84], improvement in knee function, and the prolongation to the development of osteoarthritis [85]. Many patients require an ACLR in order to participate in their preferred athletic activities. It is important that patients are provided with an overview of the evidence base so that they can make informed decision regarding ACLR. With the plethora of research articles being published on the topic and accessibility of the internet, patients are more inclined to be given the choice of graft types, timing of surgery, and rehabilitation required to return to normal function.

There is accumulating evidence to support the use of conservative management strategies for the ACL-injured patient [86]. Follow-up studies at 15 years after injury reported good functional and quadriceps/hamstring strength with ACL injuries treated with rehabilitation. However, many patients were required to modify their activity levels and avoidance of contact sport $[87,88]$. The KANON study (the Knee, Anterior cruciate ligament, NON-surgical versus surgical treatment) [89] found no difference in muscle power and functional tests between strength training with surgical intervention when compared to conservative management strategies at 2-5 years of followup. However, the development of osteoarthritis in the knee was reported to be increased in non-operative ACL-injured patient [90] compared a delayed progression in patients with ACLR after 15-20 years of followup [91].

Patient expectation to return to sports and normal activities is often the deciding factor to undergo ACLR [92]. Another indication for ACLR is the symptom of knee instability [93]. Current surgical management strategies include reconstruction with various grafts including the bonepatellar tendon-bone (BPTB) and hamstring tendon (HT) [94]. Further development in stem cell research pursuing biological repair of the ligament are underway. There is evidence that ACLR with BPTB and HT graft in singlebundle technique does not restore the normal kinematics of the knee [84, 95-98]. This has led to interest in examining the use of double-bundle ACLR to restore anatomical function in the knee $[99,100]$. To date, no study has investigated the effects of prehabilitation in combination with surgical reconstruction and aggressive postoperative rehabilitation on ACL-injured patients.

\section{Exercise before ACLR and the Role of Prehabilitation}

Prehabilitation is defined as "a proactive, preventive approach to exercise, diet and lifestyle changes, designed to maximise health and wellness." The concept was initially coined in the 1980s for professional athletes as a process to prevent unnecessary atrophy of muscle in order to prevent future injuries [101]. Preoperative quadriceps strength is an important predictor of the functional outcome of the knee joint after ACLR [102]. This paper focuses on exerciserelated prehabilitation in preoperative ACL patients.

Two studies have assessed quadriceps function pre- and post-operatively in patients undergoing ACLR. Elmqvist et al. found a $50 \%$ reduction in quadriceps strength in the injured leg in the first 14 weeks after injury or reconstruction [103]. After one year, functional performance was still unequal, but the injured leg had almost returned to the preoperative noninjured value. Shelbourne and Johnson measured quadriceps strength and intraoperative patellar tendon width in 540 patients before and after BPTB reconstruction [104]. Smaller patellar tendon width was related to reduction quadriceps strength in pre-operative patients. Patients with small patellar tendon width (range 20-26 mm) had significantly reduced quadriceps strength at 1 and 3 months after ACLR, compared to the medium and large patellar tendon widths at the same time periods. In addition, patients with good preoperative strength $(>90 \%$ of normal leg) had a higher postoperative strength of $57.5 \%$ and $71.6 \%$ of uninjured leg at 1 and 3 months, respectively, as compared to the group with poor pre-operative strength ( $<75 \%$ of normal leg). At 2 -year followup, the post-operative quadriceps strength was the same in all groups. Patients in this study were not subjected to pre-operative exercise regime.

7.1. Strength Training. A 5-week pre-rehabilitation strategy that included progressive muscle strengthening has been shown to significantly improve knee function, quadriceps peak torque, torque at 30 degrees of flexion, and total work in patients with ACL injury [105]. There was no change in hamstring function.

Studies that have assessed strength deficits in the quadriceps and hamstring muscles before and after reconstructive surgery harvesting the ACL graft suggest a role for ACL prehabilitation before ACLR. Keays et al. enrolled patients with chronic ACL injuries in a 4-6-week pre-rehabilitation programme followed by a minimum of 4-month rehabilitation programme after surgery [106]. Patients had BPTB ACL 
reconstruction. There was a quadriceps deficit preoperatively at different isokinetic speeds. At 6 months postoperatively, there was 22-28\% deficit between the injured and uninjured limb. There was no hamstring deficit before and after surgery. Performance in the shuttle run, side step, and carioca improved significantly. Patients wore a knee immobiliser brace locked at zero-degree extension for 2 weeks postoperatively. A major drawback of the study was the failure to include a control group. In addition, no details of the preoperative physiotherapy programme were provided regarding to the pre-operative physiotherapy programme.

7.2. Proprioception and Neuromuscular Training. ACL rupture has been shown to impair proprioception and increase the latency of reflex hamstring contraction [107]. Impaired proprioception is a contributing factor predisposing to degenerative joint disease and ongoing instability in the ACLdeficient knee. Angoules et al. prospectively studied knee proprioception following ACL reconstruction and concluded that knee proprioception returned to normal within 6 months post-operatively [108]. Rehabilitation programmes following reconstruction have also been shown to improve proprioception [109].

To date, only one study has examined the effects of preoperative management on proprioception. Beard et al. [110] compared the effects of proprioceptive versus traditional exercise regime in ACL deficient patients. The 12 -week programme consisted of 2 gym session interspersed with daily self-supervised home physiotherapy. This intervention protocol was well documented, and all patients had ACL injury confirmed by knee arthroscopy prior to recruitment. Patients subjected to proprioception regime had significantly better functionality.

A neuromuscular training programme termed the perturbation technique was introduced in 2000, which involved the use of roller and tilt board for the balancing programme. The original study by Fitzgerald et al. [111] had 26 ACLdeficient patients, with 12 in the perturbation group over a period of 10 sessions. $92 \%$ (11 out of 12 ) of patients had a successful rehabilitation compared to $50 \%$ (7 out of 14) in the standard group $(P<0.05)$. Successful rehabilitation is defined as having no episodes of "giving way" at 6-month followup. Subsequent proposed guidelines were then suggested for the nonoperative management of ACL-deficient patients [86].

An American group adopted the perturbation technique prior to ACL reconstruction with the use of rocker board and roller board in 3 different conditions. Subjects who received perturbation training were trained to focus on the somatosensory input from the weight distribution of the foot contact on the board and the afferent information coming from the lower extremity to enhance joint proprioception and muscle response. Hartigan et al. [112] investigated patients who have poor dynamic knee stability (defined as ACL noncopers) [113] who had 10 sessions of perturbation training versus strength training over a period of 3-4 weeks. The perturbation group had showed better symmetrical quadriceps strength (97\% of the injured leg) and gait
$(P=0.14)$. Training with the perturbation technique may improve neuromuscular feedback and decrease antagonistic muscle activity, therefore enhancing the quadriceps' ability to stabilize the knee dynamically during gait.

The Lund group from Sweden also looked at neuromuscular training including balance, plyometric, agility drills, and sport-specific exercises. Zätterström et al. enrolled 100 patients into 5-8-month period of supervised (SV) homebased training with inclusion of postural closed kinetic chain (CKC) versus traditional self-monitored (SM) exercises [114]. The supervised rehabilitation was better in the Lysholm scoring at 3 months $(P=0.03)$, single-leg hop test, and isometric/isokinetic muscle strength in extension at 3 and 12 months. All patients had stability test and arthroscopy within 10 days of injury. This study had several weaknesses; firstly, half of the patients from the self monitored group were transferred to the supervised group at 6 weeks due to reduced $\mathrm{ROM}$, and therefore an intention-to-treat analysis was required. Secondly, 4 patients in the SV group requested to have an ACL reconstruction. Lastly, there was mixture of patient cohorts with ACL injury as well as grades 2-3 medial collateral ligament tears.

Ageberg et al. looked at a subset of the same group of patients as Zätterström ( $n=63$ out of the original 100) and compared them to healthy volunteers $(n=60)$ [115]. Patients were assessed at 6 weeks, 3, 12, and 36 months after injury with a stabilometry device, and single-leg hop tests at the same time frames (except at 6 weeks). The neuromuscular group had shorter hop distance in both the injured and uninjured limb than in the control group at 3 months ( $P<0.001$ and $P=0.04$, resp.), but not at 12 or 36 months. When compared to the self monitored group, the single-leg hop was significantly less than the controls at all time frames. Stabilometry showed differences in both groups compared to the controls at all time frames. This study also had an intention-to-treat analysis as 14 patients were transferred from the self-monitoring to the neuromuscular group at 6-week followup. However, these two Swedish studies only examined the benefits of neuromuscular training in ACLdeficient patients undergoing conservative management.

Unlike post-operative rehabilitation programmes, very few studies have explored pre- and non-operative training to enhance joint position sense, gait stability, and muscle strength. Other clinical parameters that include electromyography, MRI, and gene expression of muscular atrophy and hypertrophy are warranted to physiologically enhance our understanding of pre-operative neuromuscular training and its effects on long-term functionality.

7.3. Home Physiotherapy. Keays et al. also looked into the effectiveness of pre-operative home-based physiotherapy [116]. This study was designed to have two matched groups of 12 chronically ACL-deficient patients awaiting reconstruction which were either assigned to receive a homebased exercise and educational programme or no prior pre-operative physiotherapy. Another group of 12 matched uninjured control subjects was also subjected to treatment. After 6 weeks, compared to the nontreated group, the treated 
ACL-deficient group showed a significant improvement in quadriceps strength from $85 \%$ and $86 \%$ to $102 \%$ and $103 \%$ at $60 \%$ and $120 \%$ s. There was no difference in outcome between the nontreated ACL-deficient group versus the treated control group. These patients did not have long-term followup, and the number of patients that underwent surgery after this period of rehabilitation remained unknown.

7.4. Surgical versus Nonsurgical. The KANON study in Sweden [117] is a randomized, controlled trial to compare a strategy of structured rehabilitation with early ACL reconstruction within 10 weeks versus structured rehabilitation with delayed ACL reconstruction offered to subjects who continue to have symptoms of knee instability. This study showed no significant difference between the two groups for primary outcome which was the Knee Injury and Osteoarthritis Outcome Score (KOOS). Interestingly, the initial strategy of structured rehabilitation alone instead of structured rehabilitation plus early ACL reconstruction resulted in surgical reconstruction being avoided in 61\% of the subjects without compromising the results. This landmark study suggests that the use of rehabilitation plus optional delayed ACL reconstruction with symptoms of instability is favoured to avoid possible reconstructions without adversely affecting outcomes. However, this study's limitations include self-reporting primary outcome and a nonequivalent control group such as sham surgery.

A side project of the KANON study [86] reported no significant differences between muscle strength and functional performance in patients with ACL injury treated with training and surgical reconstruction or training only. This study adopted the Limb Symmetrical Index (LSI) of $>90 \%$ which was considered normal $[118,119]$ and compared between the two group. Due to these recent trials on the effects of rehabilitation with and without ACL reconstruction, patients with symptomatic unstable knees should be individually assessed regarding symptoms such as knee instability and type and frequency of current and future activities. However, these studies did not investigate the independent and synergistic effects of pre-operative prehabilitation in patients who planned and ultimately underwent an ACLR.

7.5. Introducing Open Kinetic Chain (OKC) Exercises. OKC is characterized by the distal segment of an extremity being free to move such as in knee flexion or extension activity [120]. Conversely, a closed chain exercise is described as the distal segment of a limb being fixed, such as in a squat or leg press. Tagesson et al. in 2008 stressed the importance of $\mathrm{OKC}$ as a conservative nonoperative approach to improve quadriceps strength in ACL-deficient patients [121]. At 4month followup, the OKC group had greater isokinetic quadriceps strength with a LSI of 0.96 compared to 0.84 in the CKC group. The muscle activation in both was similar pre- and post-rehabilitation. The decision to allow patients to return to sports was designated when the strength LSI and single-leg hop LSI were $<15 \%$ [122]. In addition, CKC produced the same ACL strain forces as OKC [123]. In view of previous studies confirming the correlation between preand post-operative quadriceps muscle strength, examining the benefits of OKC as a prehabilitation strategy before ACLR is an interesting prospect for future research.

\section{Conclusion}

There has been a significant improvement in the management of ACL injuries since Noyes et al. proposed the usage of strength training in chronic ACL-injured patients. Rehabilitation after surgery has always been an integral component to the success of patients' recovery to normal activities. In conclusion, there are evidences suggesting the role of rehabilitation in ACL-deficient patients opted as nonoperative and post-operative training for muscle strengthening and proprioception purposes. The role of prehabilitation as a pre-operative intervention complementary to current practices is currently emerging; however, further research into preoperative resistance training in combination with proprioceptive training is required to significantly improve this arsenal of management strategies available to patients.

\section{References}

[1] M. M. Ditmyer, R. Topp, and M. Pifer, "Prehabilitation in preparation for orthopaedic surgery," Orthopaedic Nursing, vol. 21, no. 5, pp. 43-52, 2002.

[2] P. Z. Pearce, "Prehabilitation: preparing young athletes for sports," Current Sports Medicine Reports, vol. 5, no. 3, pp. 155-160, 2006.

[3] A. M. Swank, J. B. Kachelman, W. Bibeau et al., "Prehabilitation before total knee arthroplasty increases strength and function in older adults with severe osteoarthritis," Journal of Strength and Conditioning Research, vol. 25, no. 2, pp. 318325, 2011.

[4] P. R. Nielsen, L. D. Jørgensen, B. Dahl, T. Pedersen, and H. Tønnesen, "Prehabilitation and early rehabilitation after spinal surgery: randomized clinical trial," Clinical Rehabilitation, vol. 24, no. 2, pp. 137-148, 2010.

[5] A. Alkarmi, D. H. J. Thijssen, K. Albouaini et al., "Arterial prehabilitation: can exercise induce changes in artery size and function that decrease complications of catheterization?" Sports Medicine, vol. 40, no. 6, pp. 481-492, 2010.

[6] D. J. Kim, N. E. Mayo, F. Carli, D. L. Montgomery, and G. S. Zavorsky, "Responsive measures to prehabilitation in patients undergoing bowel resection surgery," Tohoku Journal of Experimental Medicine, vol. 217, no. 2, pp. 109-115, 2009.

[7] F. R. Noyes, D. S. Matthews, P. A. Mooar, and E. S. Grood, "The symptomatic anterior cruciate-deficient knee. Part II. The results of rehabilitation, activity modification, and counseling on functional disability," Journal of Bone and Joint Surgery-Series A, vol. 65, no. 2, pp. 163-174, 1983.

[8] A. Nakamae, M. Ochi, M. Deie et al., "Biomechanical function of anterior cruciate ligament remnants: how long do they contribute to knee stability after injury in patients with complete tears?" Arthroscopy, vol. 26, no. 12, pp. 1577-1585, 2010.

[9] J. Kennedy, M. P. Jackson, P. O’Kelly, and R. Moran, “Timing of reconstruction of the anterior cruciate ligament in athletes and the incidence of secondary pathology within the knee," 
Journal of Bone and Joint Surgery—Series B, vol. 92, no. 3, pp. 362-366, 2010.

[10] N. P. Thomas, A. M. Jackson, and P. M. Aichroth, "Congenital absence of the anterior cruciate ligament. A common component of knee dysplasia," Journal of Bone and Joint Surgery-Series B, vol. 67, no. 4, pp. 572-575, 1985.

[11] A. E. Ellison and E. E. Berg, "Embryology, anatomy, and function of the anterior cruciate ligament," Orthopedic Clinics of North America, vol. 16, no. 1, pp. 3-14, 1985.

[12] S. Kopf, V. Musahl, S. Tashman, M. Szczodry, W. Shen, and F. H. Fu, "A systematic review of the femoral origin and tibial insertion morphology of the ACL," Knee Surgery, Sports Traumatology, Arthroscopy, vol. 17, no. 3, pp. 213-219, 2009.

[13] K. Hara, T. Mochizuki, I. Sekiya, K. Yamaguchi, K. Akita, and T. Muneta, "Anatomy of normal human anterior cruciate ligament attachments evaluated by divided small bundles," The American Journal of Sports Medicine, vol. 37, no. 12, pp. 2386-2391, 2009.

[14] A. A. Amis and G. P. C. Dawkins, "Functional anatomy of the anterior cruciate ligament. Fibre bundle actions related to ligament replacements and injuries," Journal of Bone and Joint Surgery-Series B, vol. 73, no. 2, pp. 260-267, 1991.

[15] V. B. Duthon, C. Barea, S. Abrassart, J. H. Fasel, D. Fritschy, and J. Ménétrey, "Anatomy of the anterior cruciate ligament," Knee Surgery, Sports Traumatology, Arthroscopy, vol. 14, no. 3, pp. 204-213, 2006.

[16] R. Strocchi, V. de Pasquale, P. Gubellini et al., "The human anterior cruciate ligament: histological and ultrastructural observations," Journal of Anatomy, vol. 180, no. 3, pp. 515519, 1992.

[17] J. C. Kennedy, I. J. Alexander, and K. C. Hayes, "Nerve supply of the human knee and its functional importance," The American Journal of Sports Medicine, vol. 10, no. 6, pp. 329-335, 1982.

[18] J. Haus and Z. Halata, "Innervation of the anterior cruciate ligament," International Orthopaedics, vol. 14, no. 3, pp. 293296, 1990.

[19] T. Hogervorst and R. A. Brand, "Mechanoreceptors in joint function," Journal of Bone and Joint Surgery-Series A, vol. 80, no. 9, pp. 1365-1378, 1998.

[20] M. R. Krogsgaard, P. Dyhre-Poulsen, and T. Fischer-Rasmussen, "Cruciate ligament reflexes," Journal of Electromyography and Kinesiology, vol. 12, no. 3, pp. 177-182, 2002.

[21] E. S. Grood, W. J. Suntay, F. R. Noyes, and D. L. Butler, "Biomechanics of the knee-extension exercise. Effect of cutting the anterior cruciate ligament," Journal of Bone and Joint Surgery-Series A, vol. 66, no. 5, pp. 725-734, 1984.

[22] W. Muller, The Knee: Form, Function, and Ligament Reconstruction, Springer, New York, NY, USA, 1983.

[23] B. D. Beynnon, B. C. Fleming, R. Labovitch, and B. Parsons, "Chronic anterior cruciate ligament deficiency is associated with increased anterior translation of the tibia during the transition from non-weightbearing to weightbearing," Journal of Orthopaedic Research, vol. 20, no. 2, pp. 332-337, 2002.

[24] M. T. Gabriel, E. K. Wong, S. L. Y. Woo, M. Yagi, and R. E. Debski, "Distribution of in situ forces in the anterior cruciate ligament in response to rotatory loads," Journal of Orthopaedic Research, vol. 22, no. 1, pp. 85-89, 2004.

[25] M. Sakane, R. J. Fox, S. L. Y. Woo, G. A. Livesay, G. Li, and F. $\mathrm{H}$. Fu, "In situ forces in the anterior cruciate ligament and its bundles in response to anterior tibial loads," Journal of Orthopaedic Research, vol. 15, no. 2, pp. 285-293, 1997.
[26] H. Matsumoto, Y. Suda, T. Otani, Y. Niki, B. B. Seedhom, and K. Fujikawa, "Roles of the anterior cruciate ligament and the medial collateral ligament in preventing valgus instability," Journal of Orthopaedic Science, vol. 6, no. 1, pp. 28-32, 2001.

[27] N. Lopomo, S. Zaffagnini, C. Signorelli et al., "An original clinical methodology for non-invasive assessment ofpivotshift test," Computer Methods in Biomechanics and Biomedical Engineering. In press.

[28] S. L. Y. Woo, J. M. Hollis, D. J. Adams, R. M. Lyon, and S. Takai, "Tensile properties of the human femur-anterior cruciate ligament-tibia complex. The effects of specimen age and orientation," The American Journal of Sports Medicine, vol. 19, no. 3, pp. 217-225, 1991.

[29] T. P. Andriacchi and D. Birac, "Functional testing in the anterior cruciate ligament-deficient knee," Clinical Orthopaedics and Related Research, no. 288, pp. 40-47, 1993.

[30] M. Berchuck, T. P. Andriacchi, B. R. Bach, and B. Reider, "Gait adaptations by patients who have a deficient anterior cruciate ligament," Journal of Bone and Joint Surgery-Series A, vol. 72, no. 6, pp. 871-877, 1990.

[31] P. Devita, P. B. Hunter, and W. A. Skelly, "Effects of a functional knee brace on the biomechanics of running," Medicine and Science in Sports and Exercise, vol. 24, no. 7, pp. 797-806, 1992.

[32] J. M. Timoney, W. S. Inman, P. M. Quesada et al., "Return of normal gait patterns after anterior cruciate ligament reconstruction," The American Journal of Sports Medicine, vol. 21, no. 6, pp. 887-889, 1993.

[33] T. P. Branch, R. Hunter, and M. Donath, "Dynamic EMG analysis of anterior cruciate deficient legs with and without bracing during cutting," The American Journal of Sports Medicine, vol. 17, no. 1, pp. 35-41, 1989.

[34] S. Kålund, T. Sinkjaer, L. Arendt-Nielsen, and O. Simonsen, "Altered timing of hamstring muscle action in anterior cruciate ligament deficient patients," The American Journal of Sports Medicine, vol. 18, no. 3, pp. 245-248, 1990.

[35] P. Lass, S. Kaalund, S. LeFevre, L. Arendt-Nielsen, T. Sinkjaer, and O. Simonsen, "Muscle coordination following rupture of the anterior cruciate ligament. Electromyographic studies of 14 patients," Acta Orthopaedica Scandinavica, vol. 62, no. 1, pp. 9-14, 1991.

[36] T. J. Limbird, R. Shiavi, M. Frazer, and H. Borra, "EMG profiles of knee joint musculature during walking: changes induced by anterior cruciate ligament deficiency," Journal of Orthopaedic Research, vol. 6, no. 5, pp. 630-638, 1988.

[37] R. Shiavi, L. Q. Zhang, T. Limbird, and M. A. Edmondstone, "Pattern analysis of electromyographic linear envelopes exhibited by subjects with uninjured and injured knees during free and fast speed walking," Journal of Orthopaedic Research, vol. 10, no. 2, pp. 226-236, 1992.

[38] T. Sinkjær and L. Arendt-Nielsen, "Knee stability and muscle coordination in patients with anterior cruciate ligament injuries: an electromyographic approach," Journal of Electromyography and Kinesiology, vol. 1, no. 3, pp. 209-217, 1991.

[39] J. E. Tibone and T. J. Antich, "A biomechanical analysis of anterior cruciate ligament reconstruction with the patellar tendon. A two year followup," The American Journal of Sports Medicine, vol. 16, no. 4, pp. 332-335, 1988.

[40] S. Hirokawa, M. Solomonow, Z. Luo, Y. Lu, and R. D'Ambrosia, "Muscular co-contraction and control of knee stability," Journal of Electromyography and Kinesiology, vol. 1, no. 3, pp. 199-208, 1991. 
[41] K. S. Rudolph, M. E. Eastlack, M. J. Axe, and L. SnyderMackler, "Movement patterns after anterior cruciate ligament injury: a comparison of patients who compensate well for the injuryand those who require operative stabilization," Journal of Electromyography and Kinesiology, vol. 8, no. 6, pp. 349-362, 1998.

[42] S. Hirokawa, M. Solomonow, Y. Lu, Z. P. Lou, and R. D'Ambrosia, "Anterior-posterior and rotational displacement of the tibia elicited by quadriceps contraction," The American Journal of Sports Medicine, vol. 20, no. 3, pp. 299306, 1992.

[43] P. Renstrom, S. W. Arms, and T. S. Stanwyck, "Strain within the anterior cruciate ligament during hamstring and quadriceps activity," The American Journal of Sports Medicine, vol. 14, no. 1, pp. 83-87, 1986.

[44] R. Shiavi, T. Limbird, H. Borra, and M. A. Edmondstone, "Electromyography profiles of knee joint musculature during pivoting: changes induced by anterior cruciate ligament deficiency," Journal of Electromyography and Kinesiology, vol. 1, no. 1, pp. 49-57, 1991.

[45] K. S. Rudolph, M. J. Axe, T. S. Buchanan, J. P. Scholz, and L. Snyder-Mackler, "Dynamic stability in the anterior cruciate ligament deficient knee," Knee Surgery, Sports Traumatology, Arthroscopy, vol. 9, no. 2, pp. 62-71, 2001.

[46] P. Bulgheroni, M. V. Bulgheroni, L. Andrini, P. Guffanti, and A. Giughello, "Gait patterns after anterior cruciate ligament reconstruction," Knee Surgery, Sports Traumatology, Arthroscopy, vol. 5, no. 1, pp. 14-21, 1997.

[47] D. T. Davy and M. L. Audu, "A dynamic optimization technique for predicting muscle forces in the swing phase of gait," Journal of Biomechanics, vol. 20, no. 2, pp. 187-201, 1987.

[48] A. Fuentes, N. Hagemeister, P. Ranger, T. Heron, and J. A. de Guise, "Gait adaptation in chronic anterior cruciate ligament-deficient patients: pivot-shift avoidance gait," Clinical Biomechanics, vol. 26, no. 2, pp. 181-187, 2011.

[49] B. Gao and N. N. Zheng, "Alterations in three-dimensional joint kinematics of anterior cruciate ligament-deficient and -reconstructed knees during walking," Clinical Biomechanics, vol. 25, no. 3, pp. 222-229, 2010.

[50] W. J. Hurd and L. Snyder-Mackler, "Knee instability after acute ACL rupture affects movement patterns during the mid-stance phase of gait," Journal of Orthopaedic Research, vol. 25, no. 10, pp. 1369-1377, 2007.

[51] F. C. Anderson and M. G. Pandy, "Dynamic optimization of human walking," Journal of Biomechanical Engineering, vol. 123, no. 5, pp. 381-390, 2001.

[52] F. E. Zajac, R. R. Neptune, and S. A. Kautz, "Biomechanics and muscle coordination of human walking: part I: introduction to concepts, power transfer, dynamics and simulations," Gait and Posture, vol. 16, no. 3, pp. 215-232, 2002.

[53] W. Liu and M. E. Maitland, "The effect of hamstring muscle compensation for anterior laxity in the ACL-deficient knee during gait," Journal of Biomechanics, vol. 33, no. 7, pp. 871$879,2000$.

[54] V. R. Edgerton, R. R. Roy, D. L. Allen, and R. J. Monti, "Adaptations in skeletal muscle disuse or decreased-use atrophy," American Journal of Physical Medicine and Rehabilitation, vol. 81, no. 11, pp. S127-S147, 2002.

[55] G. Ferretti, H. E. Berg, A. E. Minetti, C. Moia, S. Rampichini, and M. V. Narici, "Maximal instantaneous muscular power after prolonged bed rest in humans," Journal of Applied Physiology, vol. 90, no. 2, pp. 431-435, 2001.
[56] D. B. Thomason and F. W. Booth, "Atrophy of the soleus muscle by hindlimb unweighting," Journal of Applied Physiology, vol. 68, no. 1, pp. 1-12, 1990.

[57] B. Y. Zhi, F. Gao, Z. F. Han, and J. P. Jin, "Differential regulation of myofilament protein isoforms underlying the contractility changes in skeletal muscle unloading," American Journal of Physiology, vol. 292, no. 3, pp. C1192-C1203, 2007.

[58] R. J. Talmadge, R. R. Roy, and V. R. Edgerton, "Distribution of myosin heavy chain isoforms in non-weight-bearing rat soleus muscle fibers," Journal of Applied Physiology, vol. 81, no. 6, pp. 2540-2546, 1996.

[59] F. W. Booth, "Time course of muscular atrophy during immobilization of hindlimbs in rats," Journal of Applied Physiology Respiratory Environmental and Exercise Physiology, vol. 43, no. 4, pp. 656-661, 1977.

[60] R. L. Lieber, J. O. Friden, A. R. Hargens, L. A. Danzig, and D. H. Gershuni, "Differential response of the dog quadriceps muscle to external skeletal fixation of the knee," Muscle and Nerve, vol. 11, no. 3, pp. 193-201, 1988.

[61] M. D. de Boer, C. N. Maganaris, O. R. Seynnes, M. J. Rennie, and M. V. Narici, "Time course of muscular, neural and tendinous adaptations to 23 day unilateral lower-limb suspension in young men," Journal of Physiology, vol. 583, no. 3, pp. 1079-1091, 2007.

[62] F. W. Booth, "Effect of limb immobilization on skeletal muscle," Journal of Applied Physiology Respiratory Environmental and Exercise Physiology, vol. 52, no. 5, pp. 1113-1118, 1982.

[63] D. B. Thomason, R. B. Biggs, and F. W. Booth, "Protein metabolism and $\beta$-myosin heavy-chain mRNA in unweighted soleus muscle," American Journal of Physiology, vol. 257, no. 2, pp. R300-R305, 1989.

[64] D. F. Goldspink, A. J. Morton, P. Loughna, and G. Goldspink, "The effect of hypokinesia and hypodynamia on protein turnover and the growth of four skeletal muscles of the rat," Pflugers Archiv European Journal of Physiology, vol. 407, no. 3, pp. 333-340, 1986.

[65] M. R. Deschenes, J. A. Giles, R. W. McCoy, J. S. Volek, A. L. Gomez, and W. J. Kraemer, "Neural factors account for strength decrements observed after short-term muscle unloading," American Journal of Physiology, vol. 282, no. 2, pp. R578-R583, 2002.

[66] M. V. Hurley, "The effects of joint damage on muscle function, proprioception and rehabilitation," Manual Therapy, vol. 2, no. 1, pp. 11-17, 1997.

[67] G. Zachařová, H. Knotková-Urbancová, P. Hník, and T. Soukup, "Nociceptive atrophy of the rat soleus muscle induced by bone fracture: a morphometric study," Journal of Applied Physiology, vol. 82, no. 2, pp. 552-557, 1997.

[68] J. P. A. Dewald, P. S. Pope, J. D. Given, T. S. Buchanan, and W. Z. Rymer, "Abnormal muscle coactivation patterns during isometric torque generation at the elbow and shoulder in hemiparetic subjects," Brain, vol. 118, no. 2, pp. 495-510, 1995.

[69] T. R. Nichols, T. C. Cope, and T. A. Abelew, "Rapid spinal mechanisms of motor coordination," Exercise and Sport Sciences Reviews, vol. 27, pp. 255-284, 1999.

[70] T. Fukunaga, M. Miyatani, M. Tachi, M. Kouzaki, Y. Kawakami, and H. Kanehisa, "Muscle volume is a major determinant of joint torque in humans," Acta Physiologica Scandinavica, vol. 172, no. 4, pp. 249-255, 2001.

[71] J. Lexell, C. C. Taylor, and M. Sjostrom, "What is the cause of the ageing atrophy? Total number, size and proportion of different fiber types studied in whole vastus lateralis muscle 
from 15- to 83-year-old men," Journal of the Neurological Sciences, vol. 84, no. 2-3, pp. 275-294, 1988.

[72] H. E. Berg, L. Larsson, and P. A. Tesch, "Lower limb skeletal muscle function after 6 week of bed rest," Journal of Applied Physiology, vol. 82, no. 1, pp. 182-188, 1997.

[73] H. E. Berg, G. A. Dudley, T. Haggmark, H. Ohlsen, and P. A. Tesch, "Effects of lower limb unloading on skeletal muscle mass and function in humans," Journal of Applied Physiology, vol. 70, no. 4, pp. 1882-1885, 1991.

[74] R. R. Patel, D. E. Hurwitz, C. A. Bush-Joseph, B. R. Bach Jr., and T. P. Andriacchi, "Comparison of clinical and dynamic knee function in patients with anterior cruciate ligament deficiency," The American Journal of Sports Medicine, vol. 31, no. 1, pp. 68-74, 2003.

[75] Y. Konishi, H. Konishi, and T. Fukubayashi, "Gamma loop dysfunction in quadriceps on the contralateral side in patients with ruptured ACL," Medicine and Science in Sports and Exercise, vol. 35, no. 6, pp. 897-900, 2003.

[76] Y. Konishi, T. Fukubayashi, and D. Takeshita, "Mechanism of quadriceps femoris muscle weakness in patients with anterior cruciate ligament reconstruction," Scandinavian Journal of Medicine and Science in Sports, vol. 12, no. 6, pp. 371-375, 2002.

[77] J. E. Stevens, S. Binder-Macleod, and L. Snyder-Mackler, "Characterization of the human quadriceps muscle in active elders," Archives of Physical Medicine and Rehabilitation, vol. 82, no. 7, pp. 973-978, 2001.

[78] T. L. Chmielewski, S. Stackhouse, M. J. Axe, and L. SnyderMackler, "A prospective analysis of incidence and severity of quadriceps inhibition in a consecutive sample of 100 patients with complete acute anterior cruciate ligament rupture," Journal of Orthopaedic Research, vol. 22, no. 5, pp. 925-930, 2004.

[79] M. Lewek, K. Rudolph, M. Axe, and L. Snyder-Mackler, “The effect of insufficient quadriceps strength on gait after anterior cruciate ligament reconstruction," Clinical Biomechanics, vol. 17, no. 1, pp. 56-63, 2002.

[80] P. Devita, T. Hortobagyi, J. Barrier et al., "Gait adaptations before and after anterior cruciate ligament reconstruction surgery," Medicine and Science in Sports and Exercise, vol. 29, no. 7, pp. 853-859, 1997.

[81] K. D. Shelbourne and D. A. Foulk, "Timing of surgery in acute anterior cruciate ligament tears on the return of quadriceps muscle strength after reconstruction using an autogenous patellar tendon graft," The American Journal of Sports Medicine, vol. 23, no. 6, pp. 686-689, 1995.

[82] T. J. Manal and L. Snyder-Mackler, "Practice guidelines for anterior cruciate ligament rehabilitation: a criterionbased rehabilitation progression," Operative Techniques in Orthopaedics, vol. 6, no. 3, pp. 190-196, 1996.

[83] M. de Carlo, K. D. Shelbourne, and K. Oneacre, "Rehabilitation program for both knees when the contralateral autogenous patellar tendon graft is used for primary anterior cruciate ligament reconstruction: a case study," Journal of Orthopaedic and Sports Physical Therapy, vol. 29, no. 3, pp. 144-159, 1999.

[84] J. M. Scarvell, P. N. Smith, K. M. Refshauge, H. R. Galloway, and K. R. Woods, "Does anterior cruciate ligament reconstruction restore normal knee kinematics? A prospective MRI analysis over two years," Journal of Bone and Joint SurgerySeries B, vol. 88, no. 3, pp. 324-330, 2006.

[85] S. L. Keays, P. A. Newcombe, J. E. Bullock-Saxton, M. I. Bullock, and A. C. Keays, "Factors involved in the development of osteoarthritis after anterior cruciate ligament surgery," The American Journal of Sports Medicine, vol. 38, no. 3, pp. 455-463, 2010.

[86] G. K. Fitzgerald, M. J. Axe, and L. Snyder-Mackler, "Proposed practice guidelines for nonoperative anterior cruciate ligament rehabilitation of physically active individuals," Journal of Orthopaedic and Sports Physical Therapy, vol. 30, no. 4, pp. 194-203, 2000.

[87] E. Ageberg, A. Pettersson, and T. Fridén, "15-Year followup of neuromuscular function in patients with unilateral nonreconstructed anterior cruciate ligament injury initially treated with rehabilitation and activity modification: a longitudinal prospective study," The American Journal of Sports Medicine, vol. 35, no. 12, pp. 2109-2117, 2007.

[88] I. Kostogiannis, E. Ageberg, P. Neuman, L. Dahlberg, T. Fridén, and H. Roos, "Activity level and subjective knee function 15 years after anterior cruciate ligament injury: a prospective, longitudinal study of nonreconstructed patients," The American Journal of Sports Medicine, vol. 35, no. 7, pp. 1135-1143, 2007.

[89] E. Ageberg, R. Thomeé, C. Neeter, K. G. Silbernagel, and E. M. Roos, "Muscle strength and functional performance in patients with anterior cruciate ligament injury treated with training and surgical reconstruction or training only: a two to five-year followup," Arthritis Care and Research, vol. 59, no. 12, pp. 1773-1779, 2008.

[90] P. Neuman, M. Englund, I. Kostogiannis, T. Fridén, H. Roos, and L. E. Dahlberg, "Prevalence of tibiofemoral osteoarthritis 15 years after nonoperative treatment of anterior cruciate ligament injury: a prospective cohort study," The American Journal of Sports Medicine, vol. 36, no. 9, pp. 1717-1725, 2008.

[91] R. Mihelic, H. Jurdana, Z. Jotanovic, T. Madjarevic, and A. Tudor, "Long-term results of anterior cruciate ligament reconstruction: a comparison with non-operative treatment with a follow-up of 17-20 years," International Orthopaedics, vol. 35, no. 7, pp. 1093-1097, 2011.

[92] O. Månsson, J. Kartus, and N. Sernert, "Health-related quality of life after anterior cruciate ligament reconstruction," Knee Surgery, Sports Traumatology, Arthroscopy, vol. 19, no. 3, pp. 479-487, 2011.

[93] S. Tagesson, Dynamic knee stability after anterior cruciate ligament injury: emphasis on rehabilitation [Ph.D. thesis], Linköping University, Linköping, Sweden, 2008, Linköping University Medical Dissertations no. 1036.

[94] K. P. Spindler, J. E. Kuhn, K. B. Freedman, C. E. Matthews, R. S. Dittus, and F. E. Harrell Jr., "Anterior cruciate ligament reconstruction autograft choice: Bone-tendon-bone versus hamstring. Does it really matter? A systematic review," The American Journal of Sports Medicine, vol. 32, no. 8, pp. 19861995, 2004.

[95] M. C. Logan, A. Williams, J. Lavelle, W. Gedroyc, and M. Freeman, "Tibiofemoral kinematics following successful anterior cruciate ligament reconstruction using dynamic multiple resonance imaging," The American Journal of Sports Medicine, vol. 32, no. 4, pp. 984-992, 2004.

[96] S. Ristanis, N. Stergiou, K. Patras, H. S. Vasiliadis, G. Giakas, and A. D. Georgoulis, "Excessive tibial rotation during high-demand activities is not restored by anterior cruciate ligament reconstruction," Arthroscopy, vol. 21, no. 11, pp. 1323-1329, 2005.

[97] C. A. Bush-Joseph, D. E. Hurwitz, R. R. Patel et al., "Dynamic function after anterior cruciate ligament reconstruction with 
autologous patellar tendon," The American Journal of Sports Medicine, vol. 29, no. 1, pp. 36-41, 2001.

[98] S. Tashman, D. Collon, K. Anderson, P. Kolowich, and W. Anderst, "Abnormal rotational knee motion during running after anterior cruciate ligament reconstruction," The American Journal of Sports Medicine, vol. 32, no. 4, pp. 975-983, 2004.

[99] F. H. Fu, "Double-bundle ACL reconstruction," Orthopedics, vol. 34, no. 4, pp. 281-238, 2011.

[100] A. Debandi, A. Maeyama, S. Lu et al., "Biomechanical comparison of three anatomic ACL reconstructions in a porcine model," Knee Surgery, Sports Traumatology, Arthroscopy, vol. 19, no. 5, pp. 728-735, 2011.

[101] J. Spain, "Prehabilitation," Clinics in Sports Medicine, vol. 4, no. 3, pp. 575-585, 1985.

[102] I. Eitzen, I. Holm, and M. A. Risberg, "Preoperative quadriceps strength is a significant predictor of knee function two years after anterior cruciate ligament reconstruction," British Journal of Sports Medicine, vol. 43, no. 5, pp. 371-376, 2009.

[103] L. G. Elmqvist, R. Lorentzon, C. Johansson, M. Långström, M. Fagerlund, and A. R. Fugl-Meyer, "Knee extensor muscle function before and after reconstruction of anterior cruciate ligament tear," Scandinavian Journal of Rehabilitation Medicine, vol. 21, no. 3, pp. 131-139, 1989.

[104] K. D. Shelbourne and B. C. Johnson, "Effects of patellar tendon width and preoperative quadriceps strength on strength return after anterior cruciate ligament reconstruction with ipsilateral bone-patellar tendon-bone autograft," The American Journal of Sports Medicine, vol. 32, no. 6, pp. 1474-1478, 2004.

[105] I. Eitzen, H. Moksnes, L. Snyder-Mackler, and M. A. Risberg, "A progressive 5-week exercise therapy program leads to significant improvement in knee function early after anterior cruciate ligament injury," Journal of Orthopaedic and Sports Physical Therapy, vol. 40, no. 11, pp. 705-721, 2010.

[106] S. L. Keays, J. Bullock-Saxton, and A. C. Keays, "Strength and function before and after anterior cruciate ligament reconstruction," Clinical Orthopaedics and Related Research, no. 373, pp. 174-183, 2000.

[107] R. L. Barrack, H. B. Skinner, and S. L. Buckley, "Proprioception in the anterior cruciate deficient knee," The American Journal of Sports Medicine, vol. 17, no. 1, pp. 1-6, 1989.

[108] A. G. Angoules, A. F. Mavrogenis, R. Dimitriou et al., "Knee proprioception following ACL reconstruction; a prospective trial comparing hamstrings with bone-patellar tendon-bone autograft," Knee, vol. 18, no. 2, pp. 76-82, 2011.

[109] S. van Grinsven, R. E. H. van Cingel, C. J. M. Holla, and C. J. M. van Loon, "Evidence-based rehabilitation following anterior cruciate ligament reconstruction," Knee Surgery, Sports Traumatology, Arthroscopy, vol. 18, no. 8, pp. 11281144, 2010.

[110] D. J. Beard, C. A. F. Dodd, H. R. Trindle, and A. H. R. W. Simpson, "Proprioception enhancement for anterior cruciate ligament deficiency. A prospective randomised trial of two physiotherapy regimes," Journal of Bone and Joint SurgerySeries B, vol. 76, no. 4, pp. 654-659, 1994.

[111] G. K. Fitzgerald, M. J. Axe, and L. Snyder-Mackler, "The efficacy of perturbation training in nonoperative anterior cruciate ligament rehabilitation programs for physically active individuals," Physical Therapy, vol. 80, no. 2, pp. 128$140,2000$.
[112] E. Hartigan, M. J. Axe, and L. Snyder-Mackler, "Perturbation training prior to ACL reconstruction improves gait asymmetries in non-copers," Journal of Orthopaedic Research, vol. 27, no. 6, pp. 724-729, 2009.

[113] T. L. Chmielewski, W. J. Hurd, and L. Snyder-Mackler, "Elucidation of a potentially destabilizing control strategy in ACL deficient non-copers," Journal of Electromyography and Kinesiology, vol. 15, no. 1, pp. 83-92, 2005.

[114] R. Zätterström, T. Fridén, A. Lindstrand, and U. Moritz, "Rehabilitation following acute anterior cruciate ligament injuries-a 12-month follow-up of a randomized clinical trial," Scandinavian Journal of Medicine and Science in Sports, vol. 10, no. 3, pp. 156-163, 2000.

[115] E. Ageberg, R. Zätterström, U. Moritz, and T. Fridén, "Influence of supervised and nonsupervised training on postural control after an acute anterior cruciate ligament rupture: a three-year longitudinal prospective study," Journal of Orthopaedic and Sports Physical Therapy, vol. 31, no. 11, pp. 632-644, 2001.

[116] S. L. Keays, J. E. Bullock-Saxton, P. Newcombe, and M. I. Bullock, "The effectiveness of a pre-operative home-based physiotherapy programme for chronic anterior cruciate ligament deficiency," Physiotherapy Research International, vol. 11, no. 4, pp. 204-218, 2006.

[117] R. B. Frobell, E. M. Roos, H. P. Roos, J. Ranstam, and L. S. Lohmander, "A randomized trial of treatment for acute anterior cruciate ligament tears," The New England Journal of Medicine, vol. 363, no. 4, pp. 331-342, 2010.

[118] A. Gustavsson, C. Neeter, P. Thomeé et al., "A test battery for evaluating hop performance in patients with an ACL injury and patients who have undergone ACL reconstruction," Knee Surgery, Sports Traumatology, Arthroscopy, vol. 14, no. 8, pp. 778-788, 2006.

[119] C. Neeter, A. Gustavsson, P. Thomeé, J. Augustsson, R. Thomeé, and J. Karlsson, "Development of a strength test battery for evaluating leg muscle power after anterior cruciate ligament injury and reconstruction," Knee Surgery, Sports Traumatology, Arthroscopy, vol. 14, no. 6, pp. 571-580, 2006.

[120] R. A. Palmitier, K. N. An, S. G. Scott, and E. Y. S. Chao, "Kinetic chain exercise in knee rehabilitation," Sports Medicine, vol. 11, no. 6, pp. 402-413, 1991.

[121] S. Tagesson, B. Öberg, L. Good, and J. Kvist, "A comprehensive rehabilitation program with quadriceps strengthening in closed versus open kinetic chain exercise in patients with anterior cruciate ligament deficiency: a randomized clinical trial evaluating dynamic tibial translation and muscle function," The American Journal of Sports Medicine, vol. 36, no. 2, pp. 298-307, 2008.

[122] M. A. Risberg, M. Mørk, H. K. Jenssen, and I. Holm, “Design and implementation of a neuromuscular training program following anterior cruciate ligament reconstruction," Journal of Orthopaedic and Sports Physical Therapy, vol. 31, no. 11, pp. 620-631, 2001.

[123] B. D. Beynnon, R. J. Johnson, B. C. Fleming, C. J. Stankewich, P. A. Renstrom, and C. E. Nichols, "The strain behavior of the anterior cruciate ligament during squatting and active flexion-extension. A comparison of an open and a closed kinetic chain exercise," The American Journal of Sports Medicine, vol. 25, no. 6, pp. 823-829, 1997. 


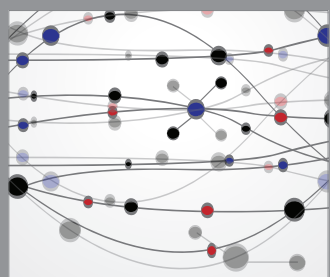

The Scientific World Journal
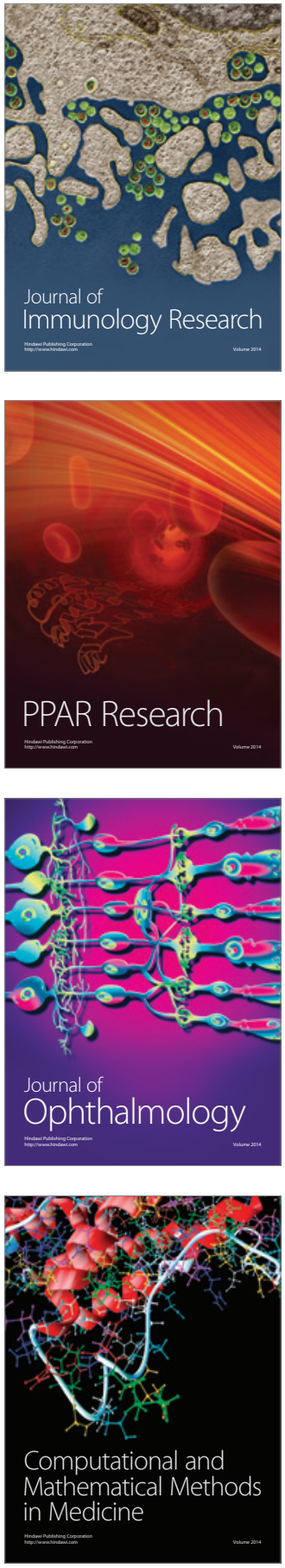

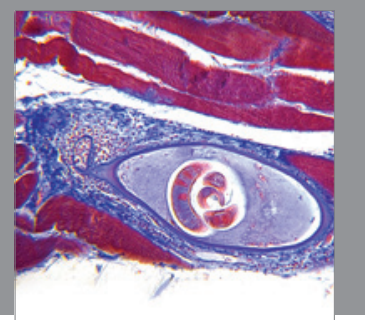

Gastroenterology

Research and Practice
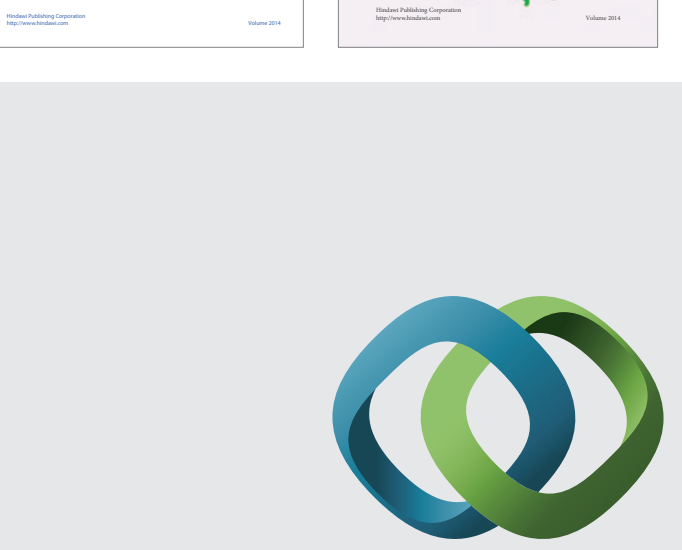

\section{Hindawi}

Submit your manuscripts at

http://www.hindawi.com
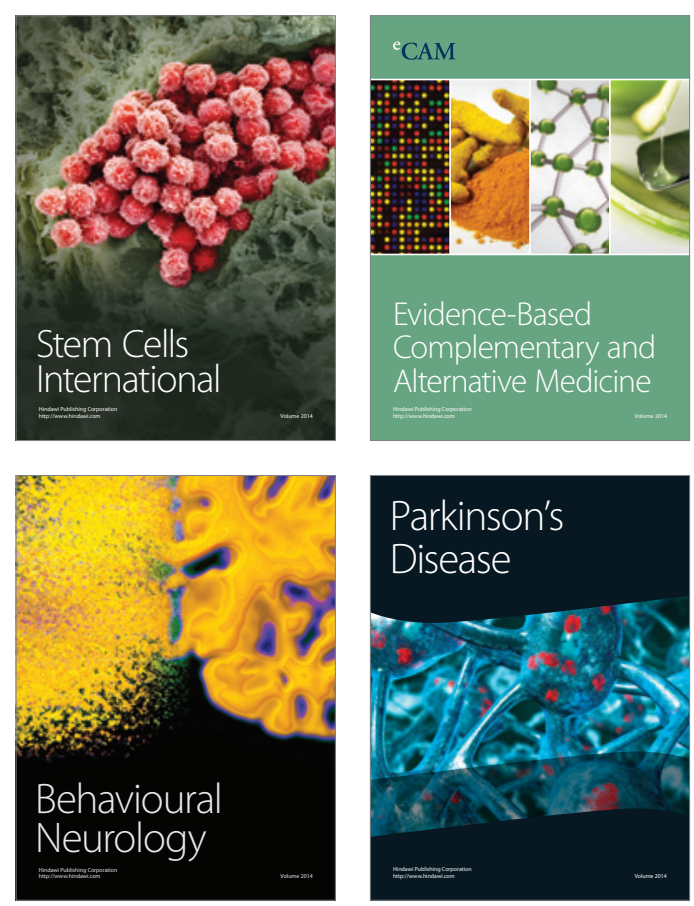

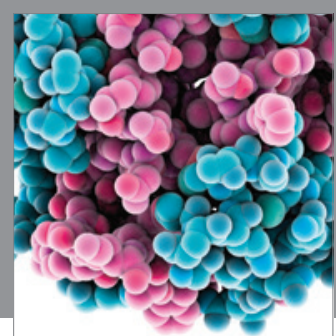

Journal of
Diabetes Research

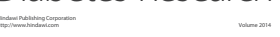

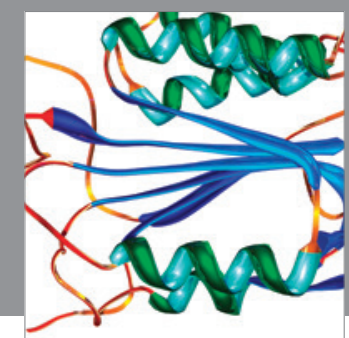

Disease Markers
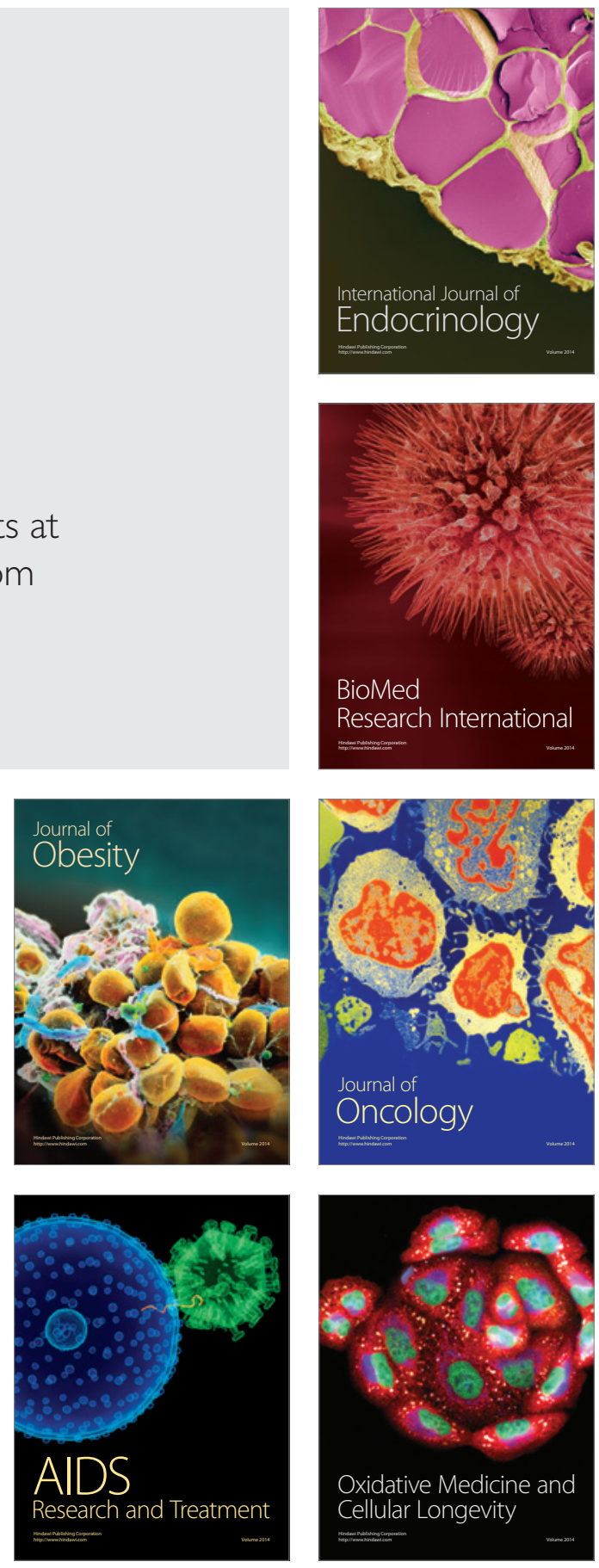